\title{
ANALYSIS EFFECTS OF OIL VISCOSITY AND TEMPERATURE ON ORBIT OF RING GEAR IN INTERNAL GEAR MOTOR AND PUMP
}

\section{Pham Trong Hoa}

University of Transport and Communications, No 3 Cau Giay Street, Hanoi, Vietnam.

ARTICLE INFO

TYPE: Research Article

Received: $11 / 7 / 2019$

Revised: $13 / 8 / 2019$

Accepted: 16/8/2019

Published online: 15/11/2019

https://doi.org/10.25073/tcsj.70.3.23

* Corresponding author

Email: phamhoamxd@utc.edu.vn; Tel: 0888599012

Abstract. Effect of oil temperature and viscosity on the ring gear orbit in the internal gear motor and pump is analyzed in this study. The mobility method is used to calculate the ring gear orbit. The mathematical model of oil viscosity and temperature is then integrated into the mobility method. The simulation results point out that the oil temperature and viscosity have great effect on the eccentricity, position angle and minimum oil film thickness. The metal - to - metal contact phenomenon occurs if internal gear motor and pump operates under high values of oil temperature or low values of oil viscosity conditions.

Keywords: Ring gear, Orbit, internal gear motor and pump, oil temperature, oil viscosity

(C) 2019 University of Transport and Communications

\section{INTRODUCTION}

Internal gear motor and pump (IGMaP) is used widely in many industrial applications such as construction machines, automobile or marine machines. An IGMaP is considered as the heart of hydraulic system. The efficiency and performance of IGMaP have much effect on the working efficiency of the whole hydraulic system and machine. A large number of studies relating to IGMaP have been carried out so far. One of the interesting topics concerning to IGMaP is the pressure and flow pulsation [1,2,3]. Determination of the internal friction moment inside IGMaP is also performed by some researchers such as Inaguma [4] in 2006 
and Paszota [5] in 2010. In addition, the efficiency of IGMaP is also attracted researchers such as Inaguma [6, 7] in 2013, Song [8] and Khalid [9] in 2016. The sound levels caused by gear motors and pumps are also received great attention from the manufacturers as well as the researchers e.g., Paffoni [10] in 2003, Casoli [11] in 2005 or Mao [12] in 2012.

The instability is an unwanted phenomenon because it can cause the solid contact between the rotor and stator. Ahmad [13], in 2010, performed a survey for the rotor contact phenomenon in rotor dynamics. He pointed out that some main parameters effect on the rotor stability such as stiffness, damping, preload and acceleration of rotor. In the study [14] in 2017, lots of experiments for IGMaP were conducted by Pham. He pointed out that the solid contact between the rotor and stator was found when instability occurred for both cases: at high pressure and low speed and low pressure and high speed conditions.

Up to now, lots of studies relating to IGMaP have been released. All of them only concerned the 'outside' resulting parameter or process of the gear pump, e.g., pressure and flow pulsation, efficiency, noise or frictional moment. Prediction of the ring gear orbit is the fundamental issue to analyse the dynamic behaviour of IGMaP. However, studies regarding to determine the effect of oil temperature and viscosity on ring gear orbit of IGMaP have been not released. The reason is that in order to calulate the ring gear orbit under the different operating conditions, it requires a mathematical model that faithfully describes the dynamic behavior. Meanwhile, there is lots of phenomena happened inside IGMaP such as the development of the internal friction, axial and radial movement of the ring gear and pressure distribution. It makes the building of an accurate mathematical model is complex. Pham in study $[15,16]$ successfully applied the mobility method to predict the ring gear orbit. The working oil is known as the blood in hydraulic system. The temperature and viscosity are the most important characteristics of working oil. The effect of oil temperature and viscosity on the ring gear orbit have been not released so far. With the proposal approach presented in this paper, effect of oil temperature and viscosity are investigated with the help of mobility method.

\section{MATHEMATICAL MODEL}

An internal gear motor and pump contains three main parts, i.e., a driving gear, ring gear and housing. The outer ring gear and inner housing is separated by oil lubrication thin film. For IGMaP, this oil lubrication is also the hydraulic oil. Figure 1 shows the cross section of internal gear motor and pump.

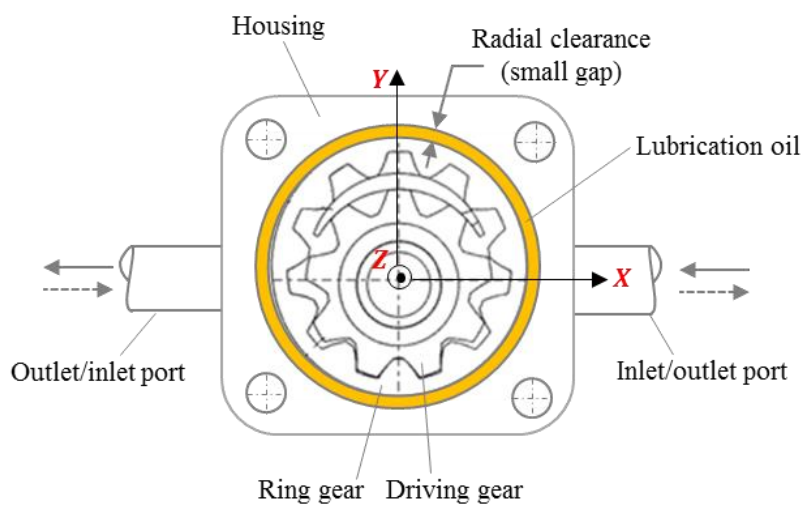

Figure 1. The section of IGMaP.

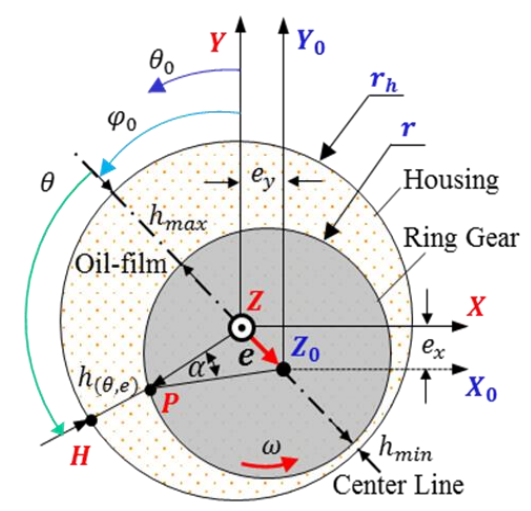

Figure 2. Geometry of the ring gear. 
During operation, the ring gear center is eccentric compared to the housing center. The value of eccentricity is dependent not only on the working pressure and rotating speed, but also on oil temperature and oil viscosity. The appearance of eccentricity leads to the minimum film thickness is decreased at some points meanwhile increased at some other points as shown in Fig. 2. The large reduction of oil film thickness can lead to the solid contact phenomenon between the outer ring gear and inner housing. Based on the geometry of IGMaP, the oil film equation is formed as follows [15]:

$$
\mathrm{h}_{(\theta, \mathrm{e})}=\mathrm{c}(1+\varepsilon \cos \theta)
$$

Where: $\varepsilon$ is the eccentricity ratio; i.e., the ratio of eccentricity to radial clearance $(\mathrm{e} / \mathrm{c})$; $\theta$ is the angle from the centre line $(\mathrm{ZZo})$ to the measured point $(\mathrm{H})$ along with the circumferential direction; $\mathrm{c}$ is the radial clearance; i.e., the difference between the radius of the housing $\left(\mathrm{r}_{\mathrm{h}}\right)$ and the ring gear $(\mathrm{r})$.

$$
\mathrm{c}=\mathrm{r}-\mathrm{r}_{\mathrm{h}}
$$

The trajectory of the ring gear center changing over time can be determined through two parameters, i.e., the eccentricity $(\varepsilon)$ and the position angle $(\varphi)$. Booker [17] introduced two mobility components thereby allowing the definition of the eccentricity and the position angle as follows,

$$
\begin{gathered}
\dot{\varepsilon}=\frac{\mathrm{F}\left(\frac{\mathrm{c}}{\mathrm{r}}\right)^{2}}{\mu \mathrm{LD}} \mathrm{M}^{\varepsilon} \\
\dot{\varphi}=\frac{\mathrm{F}\left(\frac{\mathrm{c}}{\mathrm{r}}\right)^{2}}{\mu \mathrm{LD} \varepsilon} \mathrm{M}^{\varphi}+\bar{\omega}
\end{gathered}
$$

In which, $\mathrm{F}$ is the radial force acting on the ring gear; $\mathrm{D}$ is the diameter of the ring gear; $\mathrm{L}$ is the length of the ring gear; $\mathrm{M}^{\varepsilon}, \mathrm{M}^{\varphi}$ are mobility components; $\mu$ is the dynamic oil viscosity. Details of application of mobility method for prediction of ring gear orbit as well as the computational procedure can be found in study [15]. Dynamic Viscosity of the lubricant oil as a function of temperature can be computed according to Vogel-Cameron [18] as follows,

$$
\mu_{\mathrm{T}}=\mathrm{A} \cdot \mathrm{e}^{\frac{\mathrm{B}}{\mathrm{T}+\mathrm{C}}}
$$

Where: $\mathrm{C}=95^{\circ} \mathrm{C}$ is the constant coefficient; $\mathrm{A}$ and $\mathrm{B}$ is the fluid specific constant, for HLP 46, $\mathrm{A}=0.054 \mathrm{mPa} . \mathrm{s}, \mathrm{B}=921^{\circ} \mathrm{C}$, $\mathrm{T}$ is oil temperature.

A calculation tool has been written in Matlab software to optimize the calculation time. The temperature and viscosity are integrated into the mobility method. Consequently, the effect of oil temperature and viscosity on the ring gear orbit can be analysed.

\section{NUMERICAL RESULTS AND DISCUSSION}

\subsection{Effect of oil temperature}

Effect of oil temperature can be analysed through the dynamic viscosity of working oil. 
The ring gear orbit for various values of oil temperature is presented from Fig. 3 to Fig. 10. Based on the observation from these figures, one can see that the shape of ring gear orbit is almost the same for all cases of oil temperature. For low values of oil temperature, the eccentricity has small value meanwhile the minimum film thickness has large value. The eccentricity increases with the increase of the oil temperature. This can be explained by the decrease of the dynamic viscosity regarding with the increase of the oil temperature.

From Fig. 10 one can see that the ring gear has been traversed out of the permissible circle $(\mathrm{c}=1.0)$, this means that the solid contact between the outer ring gear and inner housing has been occurred. The metal to metal contact occurred at angle position of $237^{\circ}$. The efficiency as well as the lifespan of IGMaP has been great affected owing to the solid contact. This is an unwanted phenomenon.

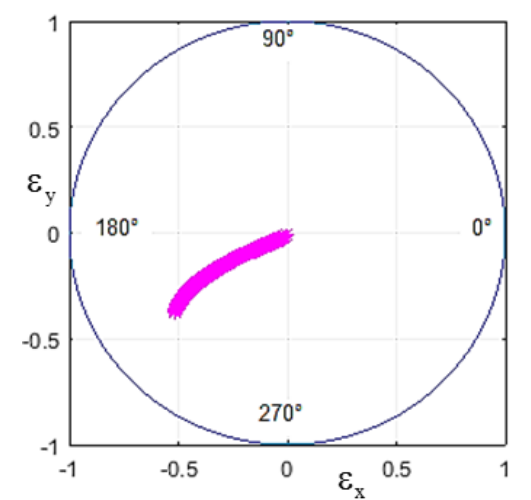

Figure 3. Oil temperature at $\mathrm{T}=-20^{\circ} \mathrm{C}$.

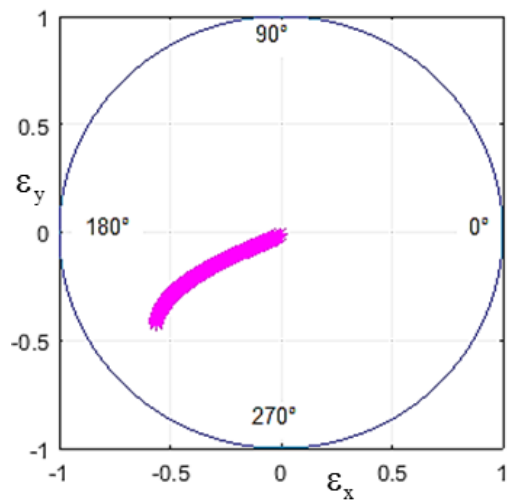

Figure 5. Oil temperature at $T=20^{\circ} \mathrm{C}$.

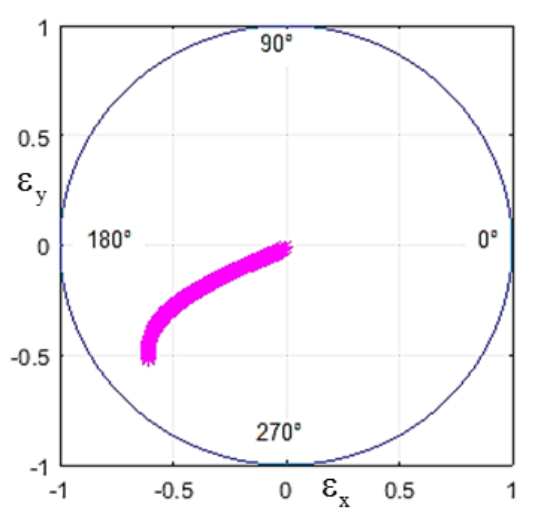

Figure 7. Oil temperature at $T=60^{\circ} \mathrm{C}$.

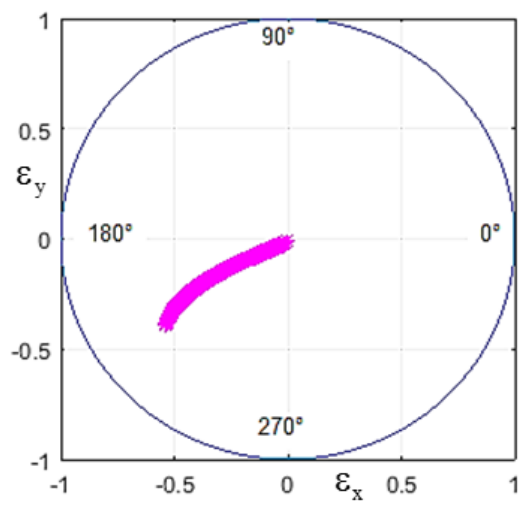

Figure 4. Oil temperature at $T=0^{\circ} \mathrm{C}$.

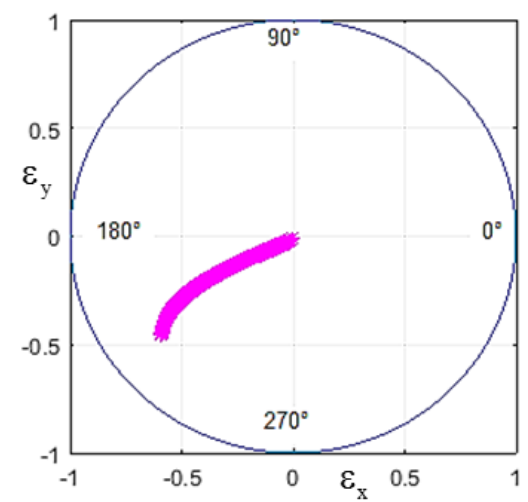

Figure 6. Oil temperature at $T=40^{\circ} \mathrm{C}$.

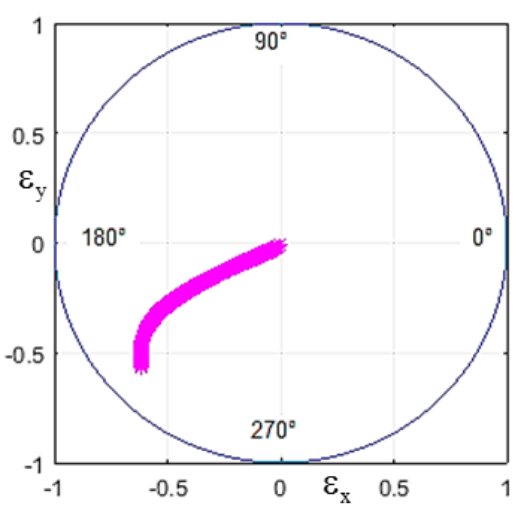

Figure 8. Oil temperature at $T=70^{\circ} \mathrm{C}$. 


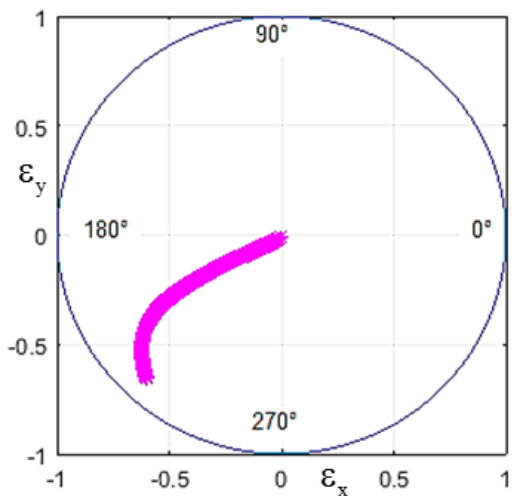

Figure 9. Oil temperature at $T=80^{\circ} \mathrm{C}$.

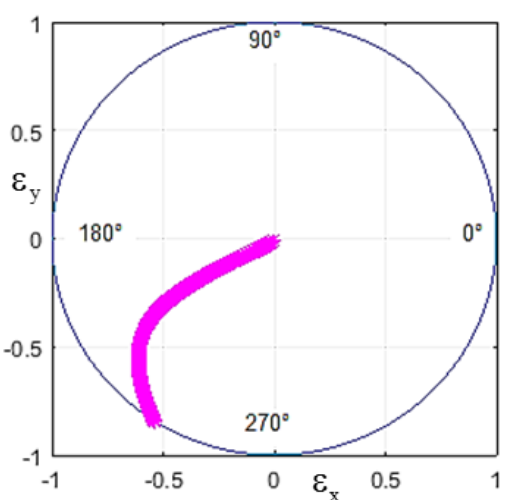

Figure 10. Oil temperature at $T=90^{\circ} \mathrm{C}$.

Effect of oil temperature on the eccentricity, position angle and minimum oil film thickness are described in Fig. 11, Fig. 12 and Fig. 13 respectively. From these figures one can see that the eccentricity and position angle increase with the increase of the oil temperature meanwhile the minimum oil film thickness decreases with the increase of the oil temperature. This means that for specific working condition if the internal gear motor and pump operates under the high values of oil temperature, the oil film thickness between the ring gear and housing will become small. It can lead to the solid contact between the ring gear and housing owing to the failure of the oil film. It should be noted and avoided in real operation.

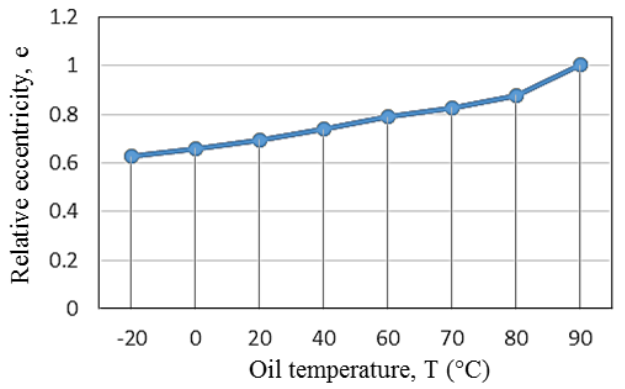

Figure 11. Eccentricity versus oil temperature.

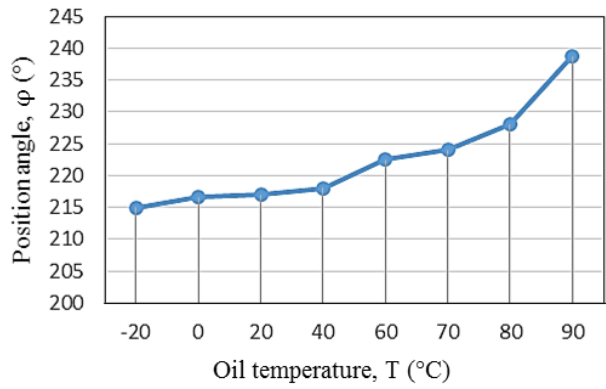

Figure 12. Position angle versus oil temperature.

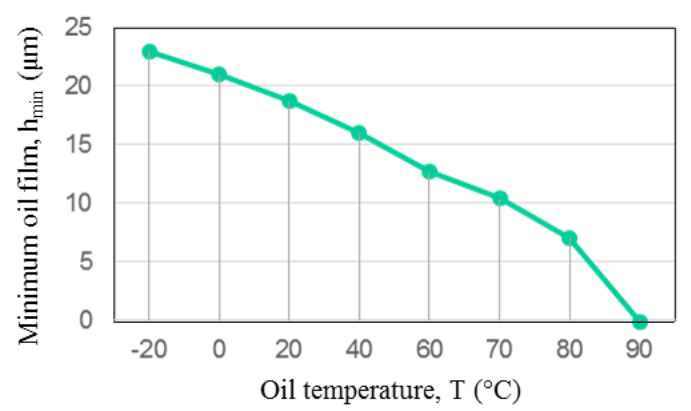

Figure 13. Minimum oil film thickness versus oil temperature.

\subsection{Effect of Oil Viscosity}

Effect of the working oil type on ring gear orbit is presented from Fig. 14 to Fig. 21. It is 
Transport and Communications Science Journal, Vol. 70, Issue 3 (09/2019), 153-161

obviously to see that the viscosity has great effect on the ring gear orbit, e.g. for low value of oil viscosity the eccentricity of ring gear has high value. It can see from Fig. 14 that the ring gear traverses out of the allowable circle $(c=1.0)$, the eccentricity excesses the maximum permissible value, $\varepsilon=1.13$. This means that the solid contact between the outer ring gear and inner housing is occurred. However, for high values of oil viscosity, the eccentricity of ring gear is reduced. The solid contact phenomenon does not appear. For example, with oil type HLP 150 , the eccentricity of ring gear is only about 0.51 .

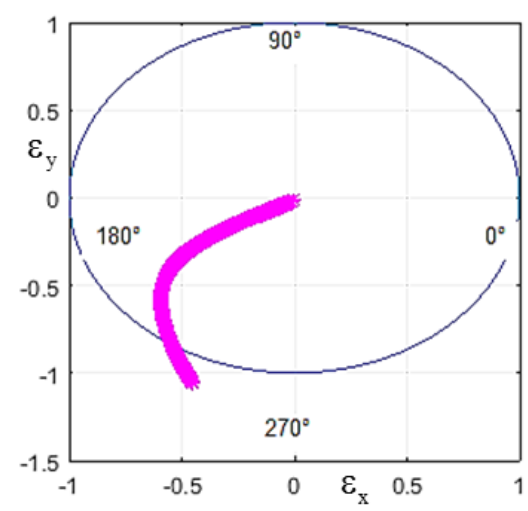

Figure 14. Oil HLP1O ( $\mu=0.0087$ Pa.s $)$.

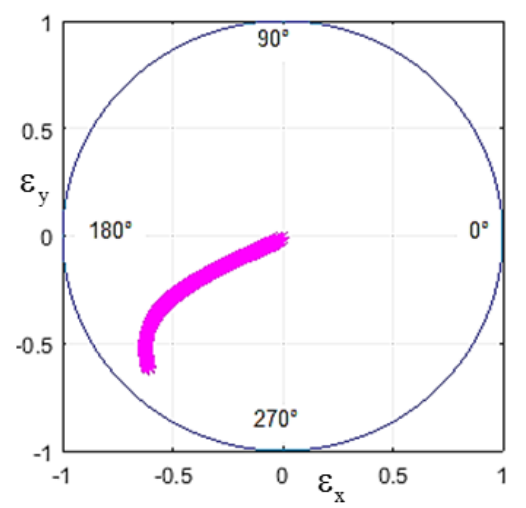

Figure 16. Oil HLP22 $(\mu=0.019$ Pa.s $)$.

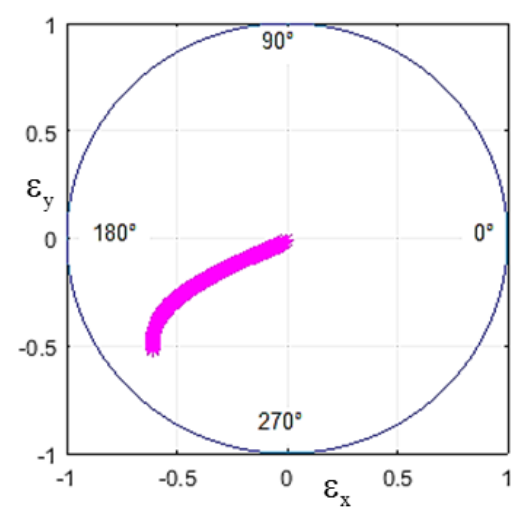

Figure 18. Oil HLP46 $(\mu=0.04$ Pa.s $)$.

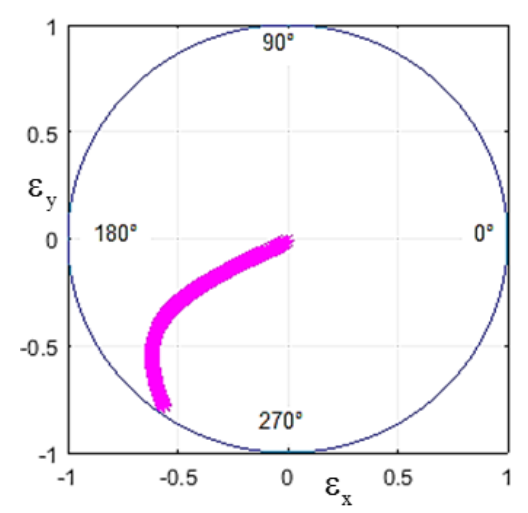

Figure 15. Oil HLP15 $(\mu=0.013 P a . S)$.

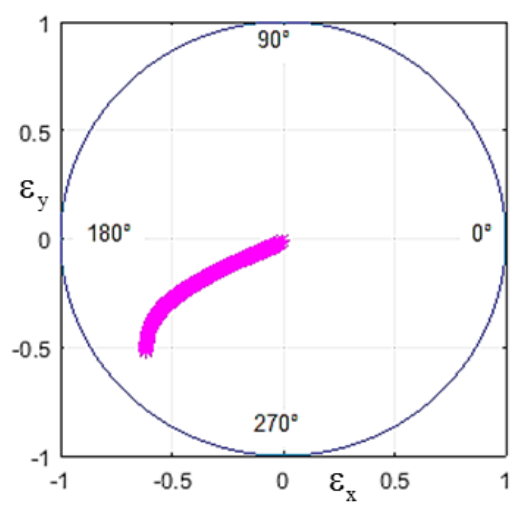

Figure 17. Oil HLP32 $(\mu=0.0278 P a . s)$.

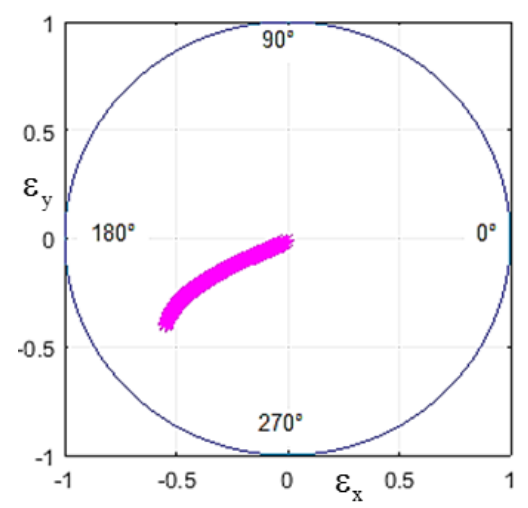

Figure 19. Oil HLP68 $(\mu=0.0591 P a . s)$. 
Transport and Communications Science Journal, Vol. 70, Issue 3 (09/2019), 153-161

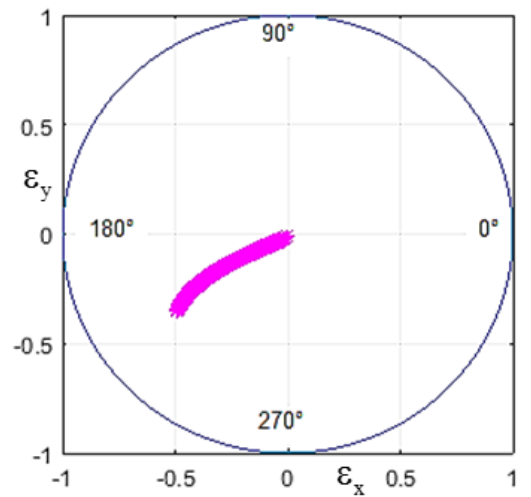

Figure 20. Oil HLP100 $(\mu=0.087$ Pa.s $)$.

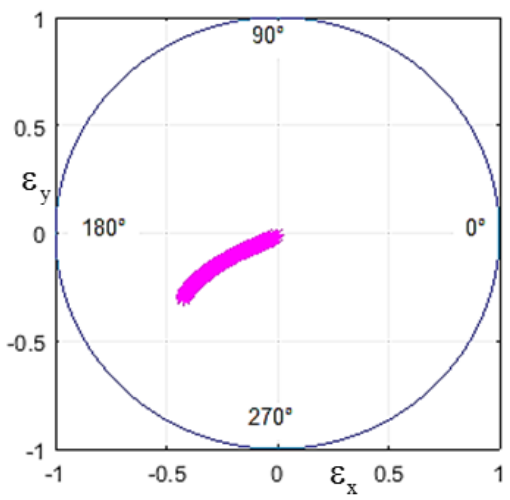

Figure 21. Oil HLP150 $(\mu=0.1305 P a . s)$.

Effect of oil viscosity on the eccentricity, position angle and minimum oil film thickness are described in Fig. 22, Fig. 23 and Fig. 24 respectively. From these figures one can see that the eccentricity and position angle decrease with the increase of the oil viscosity meanwhile the minimum oil film thickness increases with the increase of the oil viscosity. This means that for specific working condition if the internal gear motor and pump operates under the high values of oil viscosity, the oil film thickness between the ring gear and housing will become large. Consequently, it avoids the solid contact phenomenon between the outer ring gear and inner housing.

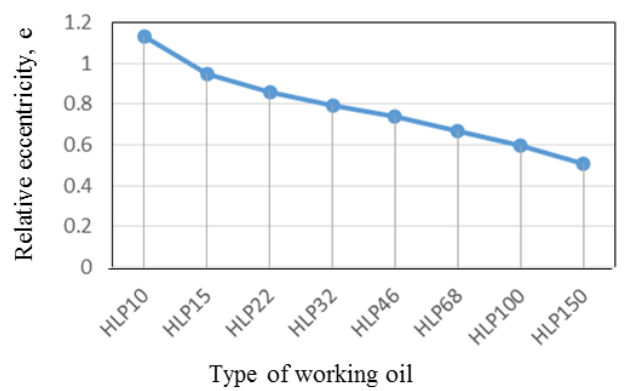

Figure 22. Eccentricity versus hydraulic oil.

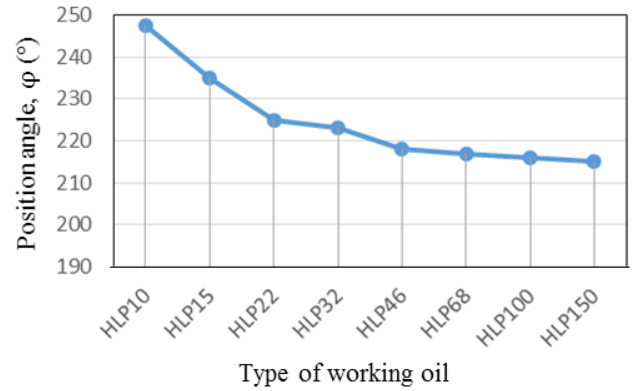

Figure 23. Position angle versus hydraulic oil.

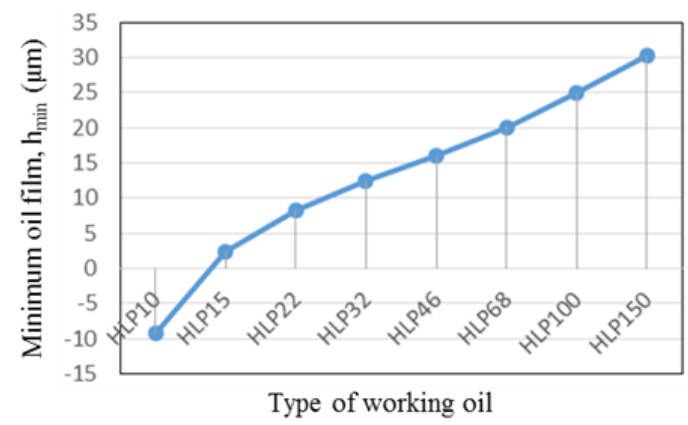

Figure 24. Minimum oil film thickness versus hydraulic oil.

\section{CONCLUSION}

Using Mobility method, the effect of oil viscosity and oil temperature on ring gear orbit can be easily analysed. Based on numerical results presented in this study, some conclusions can be drawn as follows: 
Transport and Communications Science Journal, Vol. 70, Issue 3 (09/2019), 153-161

(1) For low values of working oil temperature, the eccentricity has small value and vice versa. For specific working condition, if the temperature of working oil is sufficient high, then the ring gear will traverse out of the permissible space. Consequently, the solid contact between the outer ring gear and inner housing will occur. Thus, IGMaP should not operate at high value of oil temperature.

(2) The eccentricity, position angle and minimum film thickness are varying for different type of working oil or in other words the oil viscosity. IGMaP runs well at high values of oil viscosity. If the value of oil viscosity is too low, it can lead to the metal to metal contact phenomenon between the outer ring gear and inner housing. It is, therefore, the selection of working oil type for different working conditions must be performed carefully. Otherwise, the lifespan of IGMaP will be reduced much sooner.

\section{ACKNOWLEDGEMENTS}

This research is funded by Vietnam National Foundation for Science and Technology Development (NAFOSTED) under grant number 107.03-2019.17.

\section{REFERENCES}

[1] M. G. L. Zarotti, Reduzierung von Strömungs-pulsationen durch ein neues Konzept von Zahnradpumpen, O+P Öilhydraulik und Preumatik, 44 (2000) 33-36.

[2] C. M. R. Pipes, Spaltkompensierte Hochdruck - Innenzahnradpumpen, O+P Öilhydraulik und Preumatik, 46 (2002) 296-299.

[3] Z. Chen, Z. Lv, R. Xu., J. Liao, Simulation and Test of Gear Pump Flow Pulsation, International Journal of Fluid, Machinery and Systems, 11 (2018) 265-272. https://doi.org/10.5293/IJFMS.2018.11.3.265

[4] Y. Inaguma, Calculation of Theoretical Torque and Displacement in an Internal Gear Pump, JTEKT Eng. J. English Ed., no. 1001E (2006).

[5] Z. Paszota and C. Assembly, Theoretical and mathematical models of the torque of mechanical losses in a hydraulic rotational motor for hydrostatic drive, POLISH Marit. Res., 17 (2010) 18 - 25.

[6] Y. Inaguma, Friction torque characteristics of an internal gear pump, Proc. Inst. Mech. Eng. Part C J. Mech. Eng. Sci., 225 (2011) 1523 - 1534. https://doi.org/10.1177/0954406211399659

[7] Y. Inaguma, Mathematical Analysis of Effi ciencies in Hydraulic Pumps for Automatic Transmissions, JTEKT Eng. J. English Ed, 1011E (2014) 64 -73.

[8] W. Song, Y. Chen, and H. Zhou, Investigation of fluid delivery and trapped volume performances of Truninger gear pump by a discretization approach, Adv. Mech. Eng., 8 (2016) 1-15.

[9] D. Khalid and R. B. Weli, Factors Affecting the Characteristics of Gear Pump, 1st Int. Conf. Eng. Innov. Technol. SU-ICEIT (2016) 162 - 168.

[10] M. Rundo and A. Corvaglia, Lumped Parameters Model of a Crescent Pump, Energies, 9 (2016) 876 - 883. https://doi.org/10.3390/en9110876

[11] W. Gutbrod, Druckpulsation von Außen-und Innenzahnradpumen und deren Auswirkungen auf das Pumpengeräusch, O+P Öilhydraulik und Preumatik 19, Nr.4, (1975) 250 - 257.

[12] S. Schwarzer and P. T. Körner, Leise Innenzahnradpumpen durch Reduzierung von „Quetschöl theoretische und experimentelle, O+P Öilhydraulik und Preumatik 44 Nr.1, 3 (2016) 62 - 67.

[13] S. Admad, Rotor Casing Contact Phenomenon in Rotor Dynamics - Literature Survey, Journal of Vibration Control., 16 (2010) 1369 - 1377. 
Transport and Communications Science Journal, Vol. 70, Issue 3 (09/2019), 153-161

[14] Pham Hoa, Lutz Müller, Jürgen Weber, Theoretical and Experimental Study of Whirl and Stability Phenomenon in Internal Gear Motor/Pump, ASME/BATH FPMC Symposium on Fluid Power and Motion Control, (2017) doi: 10.1115/FPMC2017-4336).

[15] Pham, T.H., Müller, L., Weber, J., Dynamically loaded the ring gear in the internal gear motor/pump: Mobility of solution, Journal of Mechanical Science and Technology, 32 (2018) 30233035. https://doi.org/10.1007/s12206-018-0605-y

[16] Trong Hoa Pham, Analysis of the Ring Gear Orbit, Misalignment, and Stability Phenomenon of the Internal Gear Motors and Pumps, Shaker Verlag, 2018.

[17] Booker, J. F., Mobility/Impedance Methods: A Guide for Application, ASME Journal of Tribololy, 136 (2014) 024501 - 024508.

[18] Ivantysys, J., Ivantysys, M., Hydrostatische Pumpen und Motoren: Kontruktion und Berechnung, Vogel Buchverlag, 1993. 